\title{
What current and missing data can teach us about medication errors
}

\author{
William V Padula, ${ }^{1}$ Irving Steinberg ${ }^{2}$
}

${ }^{1}$ Department of Pharmaceutical \& Health Economics, University of Southern California School of Pharmacy, Los Angeles, California, USA

${ }^{2}$ Department of Clinical Pharmacy, University of Southern California School of Pharmacy, Los Angeles, California, USA

\section{Correspondence to}

Dr William V Padula, Leonard D. Schaeffer Center for Health Policy \& Economics, 635 Downey Way (VPD), University of Southern California, Los Angeles, CA, USA; padula@healthpolicy.usc.edu

Accepted 31 August 2020 Published Online First 25 September 2020

\section{SLinked}

- http://dx.doi.org/10.1136/ bmjqs-2019-010206

Check for updates

(c) Author(s) (or their employer(s)) 2021. No commercial re-use. See rights and permissions. Published by BMJ.

To cite: Padula WV, Steinberg I. BMJ Qual Saf 2021;30:89-91.
Medication errors have been a leading cause of preventable harm for decades. Assiri and colleagues report that the cost of medication error worldwide exceeds $\$ 42$ billion, or approximately 5\%-6\% of all hospitalisations. ${ }^{1}$ While this topic has been closely studied since its first appearance in scientific literature in $1953,{ }^{2}$ the problems continue to evolve alongside changes to the medication-use system. The medication-use system is a function of many elements. Widespread transitions from paper-based to electronic health records have affected drug ordering and prescribing, documentation, transcribing, dispensing, administering and monitoring in ways that challenge traditional approaches to reducing errors that predate electronic records. ${ }^{3}$ In addition, the introduction of over 7000 branded small molecules or biologics, generics and biosimilars that overlap numerous therapeutic areas increased dependence on specialty care for people with multiple chronic conditions, and navigating transitions throughout the range of primary to quaternary care have all complicated the ability of health systems to manage individual patient medication needs safely. ${ }^{4}$ Thus, solutions to address common medication errors 10 or 20 years ago may quickly become outdated in our fastpaced healthcare sector.

Medication errors can either be intercepted prior to reaching the patient or produce adverse drug events (ADEs) ranging from benign to life-threatening. Concerning prevalence rates of ADEs in hospitalised patients have been reported at $3.22 \%$ in the UK, $4.78 \%$ in Germany and $5.64 \%$ in the USA. ${ }^{5}$ For a country the size of the USA, the US Food and Drug Administration reports that this rate represents over 100000 ADEs per year. However, these data relate only to the more severe ADEs: those resulting in death, a life threatening health state, hospitalisation, disability or birth defect. ${ }^{6}$ These figures therefore encapsulate pain and suffering as captured in administrative data but do not include the multitude of patients who missed one or more days of work or school, developed symptoms necessitating an outpatient or emergency room visit, induced long-term harm, or the attendant health system costs. The data therefore give only part of the overall picture.

In contrast, based on a comprehensive analysis of UK data, the study by Elliott and colleagues in this issue attempts to illustrate the true full impact of medication errors and the associated risk of ADEs. ${ }^{7}$ Of the 237 million medication errors estimated to occur in England each year, 66 million are potentially clinically significant and result in 181 thousand hospital days and 1708 deaths at the cost of $£ 98$ million to the National Health Service. However, the aetiology and factors influencing medication errors that lead to these ADEs exceed 'ubiquitous medicine use' in the country; that is, the causes of ADEs are multifaceted. In this case, comprehensive improvement of the medication-use system should not be overlooked-and its multifaceted nature is likely to require the execution of quality improvement initiatives across many domains.

Elliott and colleagues break down medication errors by stage within the medication-use system to highlight the degree to which these issues are multifaceted. It comes as little surprise that across primary care, secondary care and care homes, prescribing, dispensing, administration and monitoring errors are prominent. However, the degree to which data are missing is also concerning and therefore may underestimate the prevalence and costs of medication errors. How can any health system, let alone an entire National Health Service devise best practices to 
reduce medication errors when data that present a substantial proportion of variability in ADEs are missing? 'No UK data available' in tables throughout Elliott and colleagues' paper (ie, no comparable UK data were available for particular settings, such as care homes) is as insightful as the numbers that are displayed since it presents an opportunity to improve quality of care informed by an investment in better data, among other needs.

As with any quality improvement initiative, beginning with a framework to reduce ADEs as a result of medication error requires an established structure. ${ }^{8}$ The 'five rights' of medication administration offer health systems one potential structure on which to ensure individuals receive the right treatment to maximise clinical benefit and minimise harm: the right patient, the right drug, the right dose, the right route and the right time. ${ }^{9}$ Building from these principles, it becomes apparent that methods and technologies for interdiction of medication error and preventable ADEs are still being refined along with variability in execution. Relatively simple solutions such as clear prescription labelling and safe packaging, multiple prescriber and pharmacy tracking to capture drug interaction risk, along with information sharing and advances in drug therapy stewardship, are examples of processes around which to build a quality improvement programme from the five rights structure that may achieve reduced rates of ADEs. ${ }^{4}$ Further targeting of these improvements within health system components where medication errors are most common, such as ambulatory and primary care settings and transitions of care, would represent efficient use of healthcare resources to reduce ADEs. ${ }^{1}$

By addressing issues in primary care and outpatient settings, the healthcare sector would also minimise the number of ADEs that result in more expensive secondary, tertiary and quaternary care, thereby increasing the probability of additional drug-drug interactions or other risks of medication errors. Further to this are settings and spaces where prescription practices are engaged, fulfilled and monitored. Providers and pharmacists rarely coexist in the same clinical settings in primary, outpatient and ambulatory care as they do in tertiary and quaternary care where the medical community has already recognised the importance of including pharmacists in patient rounds to review and reconcile medication errors. ${ }^{10}$ Past studies have noted that when the pharmacist is part of a clinical team to address patient needs within complex medication strategies, reductions in ADEs can be achieved throughout various healthcare settings. ${ }^{11-13}$ While the physically aligned presence of providers and pharmacists may not be as straightforward to facilitate in primary and outpatient care, increased telecommunication throughout the medication use process, including computer order entry and medication reconciliation, could resolve issues that may otherwise lead to medication errors and subsequent ADEs.

As the research of Elliott $e t a l^{7}$ and other findings highlight, ADEs are a costly, harmful issue that remains prevalent in global healthcare. The added complexity created by layering healthcare delivery across many settings of primary and specialty care creates gaps in communication where prescribers lack means or availability to actively communicate with pharmacists to identify and resolve potential medication errors. The sheer increase in volumes of prescription medications that outpaces process efficiencies also challenges the ability of these two stakeholders to communicate directly on a per-patient basis. However, medication reviews focused on patients who take multiple prescriptions, have debilitating long-term conditions or have recently experienced acute decompensation that could make them particularly vulnerable to repeat episodes are an important focus for whom to narrow the degree of communication by default over medication review. ${ }^{14}$

Beyond these suggestions for quality improvement based on current information, the study by Elliott and colleagues highlights the need for additional data to further direct efforts towards efficient means of sustaining reduced ADE rates. Missing data are prevalent throughout the field of ADE outcomes, either because medication errors fail to meet the threshold that institutions such as the US Food and Drug Administration set for a sentinel event or because such errors go completely unnoticed without being recorded as an episode within the health system. Many nations facing the reality of spending millions on ADEs could more proactively invest in improved reporting systems to precisely capture medication errors data, and which instances lead to minor as opposed to major ADEs, and the systems and clinical factors predicting them. These investments in better and broader data collection and quality improvement programme implementation often frighten away health system directors who fail to recognise the balance between action and reaction. Elliott and colleagues' expected value of the economic burden of ADE is almost certainly an underestimate. If much of the data on ADEs are missing from the UK system, especially at transitions of care, and other ADEs go under-reported, then the current estimate of $£ 98$ million per annum is lower than the true medical and societal cost of this issue, including non-monetary clinical disutility. The alternative cost scenario that Elliott and colleagues present in the range of $£ 728$ million per annum is perhaps a more realistic figure and one that justifies spending on quality improvement programming to offset hundreds of millions in avoidable costs.

Thus, reporting systems that captures a wider range of ADEs, coupled with improved modes of communication between providers and pharmacists, as well as a systematic effort to conduct root cause analysis that 
assist health systems to identify the nature of ADEs and evaluate potential solutions, are possibly cost-effective investments. ${ }^{15}$ The value of this information is imperative to inform more elaborate systems of medication management and target points of communication between providers and pharmacists to reconcile potential instances of medication error. ${ }^{16}$ Putting a learning health system model into place such as this-perhaps facilitated by machine learning-makes it more likely that damaging medication errors become more a part of our past history than an issue that the medical literature continues to review.

\section{Twitter William V Padula @DrWmPadula}

Funding The authors have not declared a specific grant for this research from any funding agency in the public, commercial or not-for-profit sectors.

Competing interests None declared.

Patient consent for publication Not required.

Provenance and peer review Commissioned; internally peer reviewed.

\section{REFERENCES}

1 Assiri GA, Shebl NA, Mahmoud MA, et al. What is the epidemiology of medication errors, error-related adverse events and risk factors for errors in adults managed in community care contexts? A systematic review of the International literature. BMJ Open 2018;8:e019101.

2 Byrne AK. Errors in giving medication. Am J Nurs 1953;53:829-31.

3 Tariq RA, Vashisht R, Scherbak Y, et al. Medication errors. Treasure Island (FL): StatPearls Publishing, 2020.

4 U.S. Food and Drug Administration. Think it through: a guide to managing the benefits and risks of medicines, 2016. Available: https:/www.fda.gov/drugs/resources-you-drugs/ think-it-through-guide-managing-benefits-and-risks-medicines [Accessed 18 Aug 2020].
5 Stausberg J. International prevalence of adverse drug events in hospitals: an analysis of routine data from England, Germany, and the USA. BMC Health Serv Res 2014;14:125.

6 MedWatch. MedWatch: the FDA safety information and adverse event reporting program, 2020. Available: https:// www.fda.gov/safety/medwatch-fda-safety-information-andadverse-event-reporting-program [Accessed 18 Aug 2020].

7 Elliott RA, Camacho E, Jankovic D. Economic analysis of the prevalence and clinical and economic burden of medication error in England. BMJ Qual Saf 2021;30:96-105.

8 Donabedian A. Quality assurance. structure, process and outcome. Nurs Stand 1992; 7:4-5.

9 Grissinger M. The five rights: a destination without a MAP. Pharmacy and Therapeutics 2010;35:542.

10 Alex S, Adenew AB, Arundel C, et al. Medication errors despite using electronic health records: the value of a clinical pharmacist service in reducing Discharge-Related medication errors. Qual Manag Health Care 2016;25:32-7.

11 Leape LL, Cullen DJ, Clapp MD, et al. Pharmacist participation on physician rounds and adverse drug events in the intensive care unit. JAMA 1999;282:267-70.

12 Kucukarslan SN, Peters M, Mlynarek M, et al. Pharmacists on rounding teams reduce preventable adverse drug events in hospital general medicine units. Arch Intern Med 2003;163:2014-8.

13 Kaboli PJ, Hoth AB, McClimon BJ, et al. Clinical pharmacists and inpatient medical care: a systematic review. Arch Intern Med 2006;166:955-64.

14 Meid AD, Lampert A, Burnett A, et al. The impact of pharmaceutical care interventions for medication underuse in older people: a systematic review and meta-analysis. $\mathrm{Br} \mathrm{J} \mathrm{Clin}$ Pharmacol 2015;80:768-76.

15 Braithwaite J, Westbrook MT, Mallock NA, et al. Experiences of health professionals who conducted root cause analyses after undergoing a safety improvement programme. Qual Saf Health Care 2006;15:393-9.

16 Claxton K, Griffin S, Koffijberg H, et al. How to estimate the health benefits of additional research and changing clinical practice. BMJ 2015;351:h5987. 